\title{
MODELO RELACIONAL DE UM SISTEMA DE GERENCIAMENTO DE VAGAS DE ESTÁGIO
}

\author{
Jean Pierry Felix da Silva \\ Bolsista de Iniciação Científica - IFRN Campus Natal - Zona Norte \\ E-mail: jeanpierryf@gmail.com \\ Ítalo Pinheiro de A. Figueiredo \\ Coordenação de Interação com a Sociedade - IFRN Campus Natal - Zona Norte \\ E-mail: italopinheiro@cefetrn.br
}

\section{RESUMO}

O objetivo deste trabalho é modificar o modelo atual de cadastro de alunos às vagas de estágio, tornando-o mais eficiente e acessível aos usuários que farão uso do novo sistema. Como o modelo atual é feito com fichas de papel, torna-se necessária a sua modificação para abranger um número maior de alunos cadastrados. Serão descritas as etapas para esta modificação, fazendo uso de diversas ferramentas, como Sistemas de Gerenciamento de Banco de Dados, livros didáticos e tutoriais da internet. O desenvolvimento do modelo que servirá de base ao Sistema foi desenvolvido com base nos problemas descritos na análise. A análise levou em conta as necessidades de cada tabela a ser criada, eliminando os campos desnecessários e aprimorando as tabelas para que fosse obtida uma solução mais eficiente.

PALAVRAS-CHAVE: vagas de estágio, encaminhamento, cadastro de alunos, sistema de gerenciamento de banco de dados, relacionamentos, forma normal 


\section{SISTEMA DE GERENCIAMENTO DE VAGAS DE ESTÁGIO}

\section{INTRODUÇÃO}

Atualmente, o sistema de cadastros de alunos candidatos às vagas de estágio do Campus Natal - Zona Norte do Instituto Federal de Educação, Ciência e Tecnologia do Rio Grande do Norte é constituído por fichas de papel, nas quais são armazenados os dados dos alunos, as informações necessárias para o seu encaminhamento ao estágio, bem como algumas informações do estágio em si.

Porém, devido estas informações estarem sujeitas a diversos agentes que comprometem sua integridade - como instabilidade dos dados, falta de segurança, exposição ao clima, tempo de permanência dos dados - o modelo atual não é considerado o ideal.

Faz-se necessário o uso de um novo modelo que atenda às necessidades da Coordenação de Estágios do Campus, com segurança e agilidade no acesso. Com o auxílio de um SGBD, pode-se obter esses resultados desejados. Um modelo automatizado, com um banco de dados, supre as necessidades de segurança, manutenção e organização.

O Banco de Dados auxiliará a organizar as informações, dando maior velocidade às consultas e organizando os dados de modo a obter maior integridade e segurança.

O modelo proposto tem em vista a solução dos problemas encontrados na análise e é baseado no modelo de Entidade-Relacionamento. Foi desenvolvido analisando os problemas e propondo soluções. Antes de desenvolver o modelo, foram analisados custos, tempo e facilidade de desenvolvimento, que terão de ser priorizados no momento de aplicação do modelo, na plataforma PostGreSQL. Por isso, o modelo foi criado visando suas implementação, com as informações necessárias para um melhor desempenho.

\section{METODOLOGIA}

O levantamento bibliográfico reuniu títulos que serviriam de base para a pesquisa, analisando a teoria do sistema de banco de dados, tendo em vista um conhecimento mais específico para melhor preparação das pesquisas e do trabalho.

Com o fim do levantamento bibliográfico, foi feita a análise dos SGBD’s, que é de suma importância para o projeto, pois é a fase onde se analisa o melhor Sistema de Gerenciamento de Banco de Dados para a implementação do modelo. Foram levadas em conta a facilidade de uso, a interface com o usuário, a disponibilidade na internet e o custo. O custo do SGBD é importante para que a escolha de um SGBD de qualidade e que fosse gratuito. Foram analisados o MySQL, o Firebird e o PostGreSQL. O resultado foi a escolha do PostGreSQL como o Sistema a ser utilizado, levando em conta os itens supracitados.

Na avaliação do problema, foi verificado o que iria ser preciso para realizar as consultas e quais informações seriam necessárias para cada tabela. Ficou definido, por exemplo, que a tabela "aluno" não precisaria de certas informações, como "nome dos pais”, já que isso não era relevante para seu cadastro na vaga. Essa informação, que não aparece na tabela, existe 
nas fichas de papel, tornando-se necessária uma nova análise das informações armazenadas nas fichas, para que se viesse a definir quais dados teriam necessidade de serem armazenados.

Com base nessa análise, tornou-se claro que o modelo a ser desenvolvido necessitaria de entidades e relacionamentos que correspondessem a essas expectativas. O modelo de banco de dados a ser usado foi definido como o Modelo Relacional, e para o desenvolvimento, o modelo ER.

\section{DESENVOLVIMENTO}

Para essa parte do projeto, o desenvolvimento do modelo, foi escolhido o Modelo ER (Entidade-Relacionamento), visto que ele atende às perspectivas do projeto nessa etapa. $\mathrm{O}$ modelo ER é normalmente empregado para projeções conceituais de aplicações de banco de dados, por ser um modelo de projeção de dados de alto nível.

No modelo ER, os dados são descritos como entidades, relacionamentos e atributos. O modelo ER é baseado no mundo real, com a percepção de objetos reais, como pessoas, empresas, endereços e cursos, e nas relações existentes entre eles.

"O objeto básico que um modelo ER representa é uma entidade” (Elmasri e Navathe, 2005). Uma entidade é algo que existe no mundo real (como uma pessoa ou empresa), e que possui atributos, ou seja, características que definem essa entidade. Assim, a entidade "aluno" representa um aluno candidato à vaga. Para chegar ao desenvolvimento dessa entidade, foram analisadas quais informações presentes na ficha de papel pertenciam somente ao aluno e quais pertenciam a outra entidade. Por exemplo, curso não é somente um atributo da entidade aluno, mas uma entidade que tem seus próprios atributos. Isso se torna mais claro ao observar a tabela abaixo.

Tabela 1 - Exemplo dos Possíveis campos da entidade "aluno"

\begin{tabular}{|l|}
\hline Aluno \\
\hline Matrícula do Aluno \\
\hline Curso do Aluno \\
\hline Horário Disponível para Estágio \\
\hline Horário Letivo do Aluno \\
\hline Endereço do Aluno \\
\hline Telefone do Aluno \\
\hline
\end{tabular}

Para criar as relações entre as entidades, usam-se relacionamentos, para corresponder as entidades. A entidade aluno tem um atributo chamado curso, que, por sua vez, também é uma entidade que possui atributos. Para criar uma ligação entre essas entidades, usa-se um atributo.

É necessário definir as limitações de cada relacionamento. Essas limitações são denominadas cardinalidades, e identificam o número de entidades às quais outra entidade pode ser associada. Existem quatro tipos de cardinalidade: 
- Um-para-um. Quando uma entidade A está associada a no máximo uma outra entidade B e uma entidade B está associada a no máximo uma entidade A.

- Um-para-muitos. Quando uma entidade A está associada a um número qualquer de entidades $B$, não havendo um número máximo de entidades associadas. Por exemplo, um curso pode ter vários alunos. Nessa cardinalidade, a entidade B não pode ser associada a mais de uma unidade $A$, ou seja um aluno não pode estar matriculado em vários cursos na mesma instituição.

- Muitos-para-um. A entidade A está associada a no máximo outra entidade B. Porém, nesse caso, uma entidade B pode estar associada a muitas unidades A.

- Muitos-para-muitos. Quando várias entidades A estão associadas a várias entidades B, não importando o número de entidades, tanto de A, quanto de B.

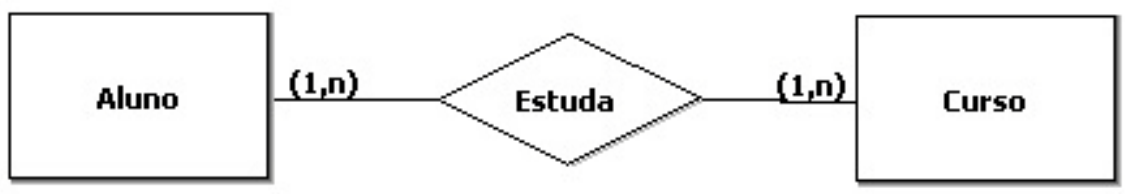

Figura 1 - Exemplo de Cardinalidade Muitos-para-um

Com base nisso, foi possível definir quais entidades seriam adotadas e seus respectivos atributos. A entidade aluno é composta dos atributos Nome, Matrícula, Curso, Horário disponível, Período letivo, Carga horária disponível, Endereço, Telefone e E-mail. Cada um desses atributos foi definido com base nas necessidades de um aluno candidato à uma vaga de estágio. Nome e matrícula são primordiais, uma vez que não há um meio identificador mais eficiente, enquanto que o curso pode ser fator determinante na escolha do aluno para a vaga, visto existirem vagas destinadas a cursos específicos. Horário disponível, Período letivo e Carga horária disponível são necessários para se definir em que período o candidato pode estagiar, de modo que sua vida acadêmica não seja interferida pelo estágio, e os atributos Endereço, Telefone e E-mail são meios de identificação de contato do aluno, uma vez que é necessário contatá-lo se ele for escolhido para a vaga. 
Definido os atributos da entidade Aluno, é necessário agora verificar as outras entidades. Definiu-se, por exemplo, que o atributo Curso, da entidade Aluno, tinha características próprias que deviam ser levadas em conta. Por isso foi criada a entidade Curso, que tem os atributos: Nome do curso, Código do curso, Períodos do curso e Período do Estágio. Nome do curso é a identificação necessária para a entidade, e Código do curso é um código único que servirá para identificar o curso entre os demais. Períodos do curso diz quantos períodos o curso tem e Período do estágio diz a partir de qual período o aluno está apto a estagiar. Observou-se que a entidade Curso e a entidade Aluno estão ligadas por um relacionamento. Assim, como o aluno estuda no curso, o relacionamento entre eles foi chamado de Estuda.

Para entender o conceito de chaves primárias, que definem quais atributos serão os identificadores principais de uma entidade, Henry F. Korth e Abraham Silberchatz (1993) dizem: "É importante ser capaz de especificar como entidades e relacionamentos são distinguidos. Conceitualmente, entidades individuais e relacionamentos são distintos, mas numa perspectiva de banco de dados a diferença entre eles precisa ser expressa em termos de seus atributos”. A chave primária, portanto, é um atributo único, que, embora apareça em outras entidades, seu conteúdo não será de nenhuma forma, igual. Por exemplo, a chave primária da entidade Aluno é o atributo Matrícula, que não pode ser igual para dois alunos.

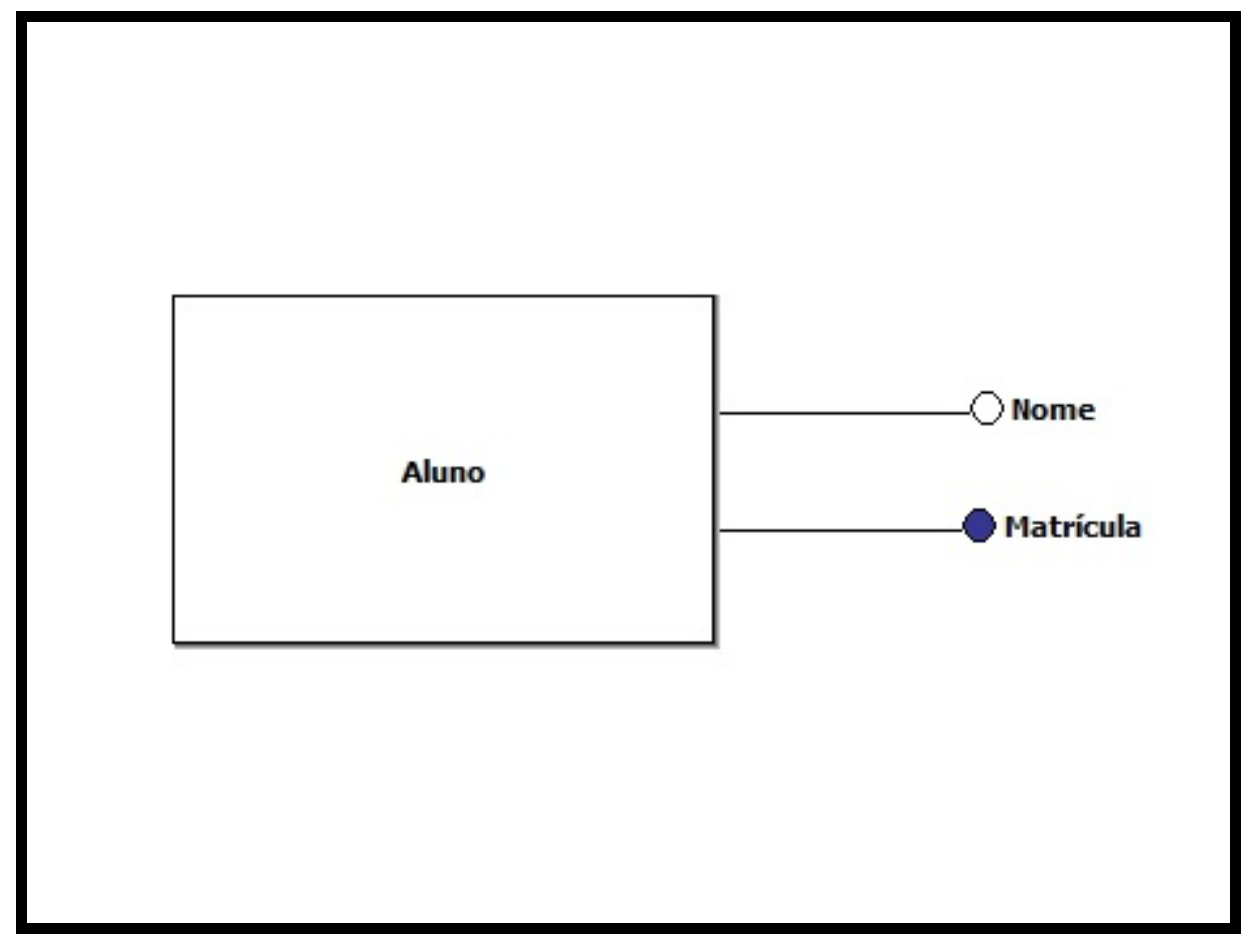

Figura 2 - Exemplo da entidade Aluno, com a chave primária Matrícula e a chave candidata Nome

Foi decido também que haveria uma entidade chamada Empresa, que ofereceria a vaga. Ela estaria ligada à entidade Vaga, que será descrita mais à frente. A entidade Empresa possui os seguintes atributos: Código da empresa, Nome da empresa, Responsável pelo estágio, Endereço da empresa, Telefone. Assim como nas entidades Aluno e Curso, os atributos Nome e Código da entidade Empresa servem como identificadores, sendo Código 
da empresa a chave primária. A vaga oferecida pela empresa gera uma entidade, visto que ela também tem características próprias. Assim, Código da vaga, Descrição da vaga, Horário, Empresa que oferece a vaga, Remuneração, Carga horária, Curso ao qual a vaga é destinada e Requisitos são atributos da entidade Vaga.

Para relacionar a entidade Vaga com a entidade Aluno, a quem a vaga é oferecida, criou-se uma nova entidade, chamada Aluno_Vaga, que conta com as chaves primárias da entidade Aluno e a entidade Vaga. Conforme diz Korth (1993), a "estrutura da chave primária depende do mapeamento de cardinalidade e da semântica do conjunto-relacionamento”. Ou seja, se duas chaves primárias de entidades diferentes puderem ser utilizadas como uma só chave primária, então, isso é possível numa nova entidade.

Com essas informações é possível definir o modelo a ser seguido. Para isso, é necessário o uso de uma ferramenta de modelagem de Diagrama Entidade-Relacionamento, disponível na internet. A ferramenta usada para desenvolver o diagrama abaixo foi o brModelo, que é gratuito. O brModelo possui todos os símbolos a serem usados num DER, por isso, foi de grande importância para o desenvolvimento do modelo.

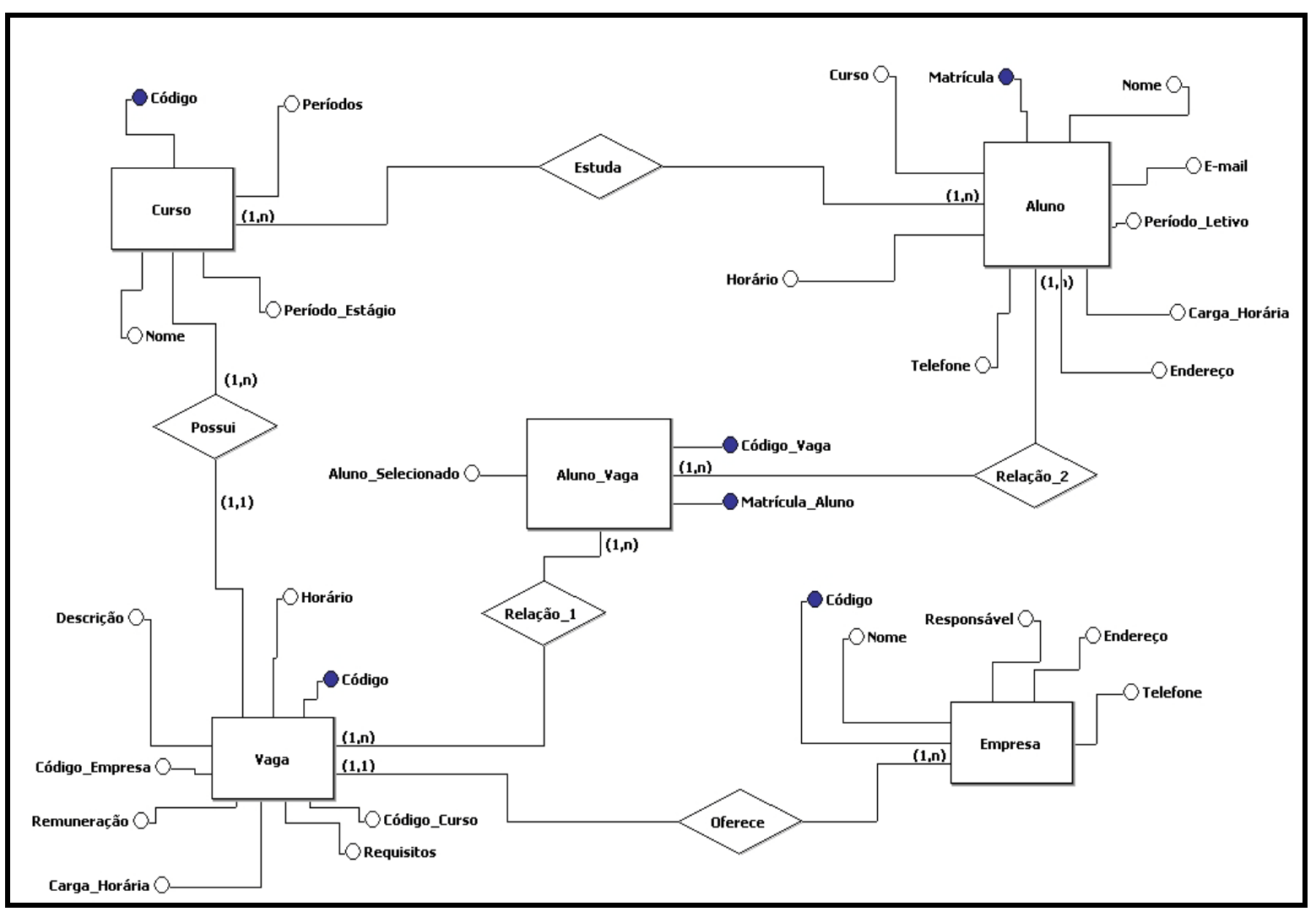

Figura 3 - Primeiro DER mostrando as entidades e relacionamentos do modelo

É interessante saber de que forma a estrutura do Diagrama Entidade-Relacionamento é constituída. Os seguintes símbolos são empregados na estrutura do DER: 
- Retângulos - São usados para representar entidades.

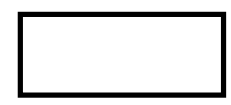

- $\quad$ Elipses - Representam atributos.

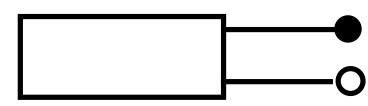

- Losangos - Representam relacionamentos.

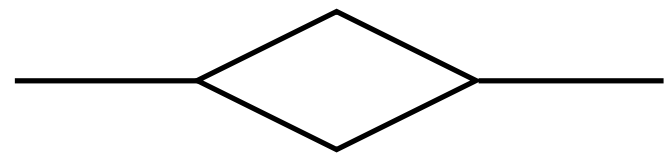

- Linhas - Ligam entidades aos relacionamentos e aos atributos

Segundo Heuser (2004), “entidades e relacionamentos [...] são normalmente representadas de forma gráfica, pois a representação textual de grafos é difícil de ler”. Por isso, usa-se as formas acima para representação de entidades, relacionamentos e atributos.

Os relacionamentos, assim como os atributos, foram definidos com base em informações do mundo real e descrevem as ligações que cada entidade tem com a outra. Abaixo, uma tabela mostrando os relacionamentos entre as entidades do DER.

Tabela 2 - Relacionamentos entre as entidades

\begin{tabular}{|l|l|l|}
\hline Entidade & Relacionamento & Entidade \\
\hline Aluno & Estuda & Curso \\
\hline Curso & Possui & Vaga \\
\hline Empresa & Oferece & Vaga \\
\hline Vaga & Relação_1 & Aluno_Vaga \\
\hline Aluno & Relação_2 & Aluno_Vaga \\
\hline
\end{tabular}

\section{RESULTADOS}

O modelo desenvolvido a partir da análise do problema, será implementado para realização de testes. De acordo com a necessidade do usuário ou com possíveis falhas do projeto, ele poderá ser modificado para adequar-se ao mesmo.

\section{CONCLUSÕES}

O modelo construído foi desenvolvido tendo em vista um melhor aproveitamento de relacionamentos entre as entidades envolvidas. Houve várias reformas no modelo desde o esquema inicial, proposto na análise. As informações desnecessárias foram removidas, resultando num modelo mais conciso e portanto, mais eficiente. 
Existirão outras versões do modelo até a implementação, onde serão ajustadas as incorreções para um processo de testes.

Algumas dificuldades surgiram no momento das relações entre as entidades Aluno e Vaga. Optou-se por unir as entidades sob uma nova entidade, Aluno_Vaga, que iria associar as entidades através de outra.

\section{REFERÊNCIAS BIBLIOGRÁFICAS}

Korth, Henry F. Sistema de Banco de Dados. MAKRON Books, 1993.

Ramez, Elmasri, Sistemas de Banco de Dados. Pearson Adson Wesley, 2005.

PostGreSQL Br http://www.postgresql.org.br

brModelo http://www.sis4.com/brModelo

Heuser, Carlos Alberto, Projeto de Banco de Dados. Editora Sagra Luzzatto, 2004. 